\title{
Insulin Degludec Once-Daily in Type 2 Diabetes: Simple or Step-Wise Titration (BEGIN: Once Simple Use)
}

Athena Philis-Tsimikas • Meryl Brod • Marcus Niemeyer •

Ann Marie Ocampo Francisco $\cdot$ Jeffrey Rothman

To view enhanced content go to www.advancesintherapy.com

Received: April 11, 2013 / Published online: June 29, 2013

(C) Springer Healthcare 2013

\section{ABSTRACT}

Introduction: Insulin degludec (IDeg) is a new basal insulin in development with a flat, ultra-long action profile that may permit dosing using a simplified titration algorithm with less frequent self-measured blood glucose (SMBG) measurements and more simplified titration steps than currently available basal insulins.

ClinicalTrials.gov \#NCT01326026.

A. Philis-Tsimikas ( $\square)$

Scripps Whittier Diabetes Institute, 9894 Genesee

Ave, La Jolla, CA 92037, USA

e-mail: Tsimikas.Athena@scrippshealth.org

M. Brod

The Brod Group, 219 Julia Ave, Mill Valley, CA

94941, USA

M. Niemeyer · A. M. Ocampo Francisco

Novo Nordisk A/S, Søborg, Denmark

J. Rothman

University Physicians Group-Research Division,

1460 Victory Blvd, Staten Island, NY 10301, USA

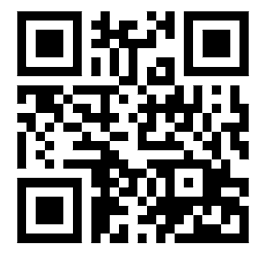

Enhanced content for Advances in Therapy articles is available on the journal web site: www.advancesintherapy.com
Methods: This 26-week, multi-center, open-label, randomized, treat-to-target study compared the efficacy and safety of IDeg administered once-daily in combination with metformin in insulin-naïve subjects with type 2 diabetes using two different patient-driven titration algorithms: a "Simple" algorithm, with dose adjustments based on one pre-breakfast SMBG measurement $(n=111)$ versus a "Step-wise" algorithm, with adjustments based on three consecutive pre-breakfast SMBG values $(n=111)$. IDeg was administered using the FlexTouch $^{\circledR}$ insulin pen (Novo Nordisk A/S, Bagsværd, Denmark), with once-weekly dose titration in both groups.

Results: Glycosylated hemoglobin $\left(\mathrm{HbA}_{1 \mathrm{c}}\right)$ decreased from baseline to week 26 in both groups (-1.09\%, IDeg Simple; $_{-0.93 \%}$, IDeg Step-wise $_{\text {. }}$. IDeg $_{\text {Simple }}$ was non-inferior to IDeg $_{\text {step-wise in }}$ lowering $\mathrm{HbA}_{1 \mathrm{c}}$ [estimated treatment difference $\left(\right.$ IDeg $_{\text {Simple }}-$ IDeg $\left._{\text {Step-wise }}\right):-0.16 \%$ points $(-0.39$; 0.07) ${ }_{95 \%}$ CI . Fasting plasma glucose was reduced ( $-3.27 \mathrm{mmol} / \mathrm{L}$, IDeg $\mathrm{Isimple}-2.68 \mathrm{mmol} / \mathrm{L}$, IDeg $\left._{\text {Step-wise }}\right)$ with no significant difference between groups. Rates of confirmed hypoglycemia [1.60, IDeg Simple; $_{1.17}$ IDeg $_{\text {Step-wise }}$ events/patient year of exposure (PYE)] and 
nocturnal confirmed hypoglycemia (0.21, IDeg $_{\text {Simple; }}$ 0.10, IDeg Step-wise $_{\text {events/PYE) were }}$ low, with no significant differences between groups. Daily insulin dose after 26 weeks was $0.61 \mathrm{U} / \mathrm{kg}$ (IDeg Simple $_{\text {) }}$ and $0.50 \mathrm{U} / \mathrm{kg}$ (IDeg Step-wise $_{\text {) }}$. No significant difference in weight change was seen between groups by week $26(+1.6 \mathrm{~kg}$, IDeg $_{\text {Simple; }}+1.1 \mathrm{~kg}$, IDeg Step-wise $_{\text {, }}$, and there were no clinically relevant differences in adverse event profiles.

Conclusion: IDeg was effective and well tolerated using either the Simple or Step-wise titration algorithm. While selection of an algorithm must be based on individual patient characteristics and goals, the ability to attain good glycemic control using a simplified titration algorithm may enable patient empowerment through self-titration, improved convenience, and reduced costs.

Keywords: Algorithm; Basal; Insulin degludec; Simple; Step-wise; Titration; Type 2 diabetes

\section{INTRODUCTION}

Achieving good glycemic control in efforts to prevent disease complications is the primary goal in the treatment of type 1 and type 2 diabetes [1]. Diabetes care guidelines and product labeling for current basal insulin analogs recommend regular blood glucose self-measurement [1-6] to help people with diabetes maintain appropriate glycemic control and become more actively involved in their healthcare [7-9]. Insulin dose is also typically determined and titrated up or down as needed according to algorithms based on blood glucose results [1]. However, challenges exist that can prevent the achievement of glycemic targets with insulin, including perceptions on the part of patients and healthcare providers (HCPs) that insulin therapy can be burdensome or too complex to manage $[10,11]$. Patients who take an active role in the management of their diabetes and titration of their insulin may feel more empowered to take charge of their self-care and have a stronger belief that their actions can influence their disease, thus leading to better treatment outcomes [12-14]. In determining how self-care can best be facilitated for patients with diabetes, the cost and burden of frequent glucose testing must be considered when designing treatment plans, as these can be significant factors when added to the health, quality of life (QoL), and financial toll of poorly controlled diabetes.

Numerous studies investigating the cost of self-measured blood glucose (SMBG) testing have found that it comprises a substantial portion of diabetes-related expenditures [15-18]. In a retrospective database analysis in the US that included more than 45,000 patients, testing accounted for $27 \%$ of diabetes care costs: total combined blood glucose testing and insulin-related costs were $\$ 2,850 \mathrm{USD} /$ patient/ year, with $\$ 772$ USD/patient/year attributed to blood glucose testing alone [18]. In other countries, testing comprises an even higher percentage of diabetes care costs (e.g., $40 \%$ in Canada [16, 17] and 42\% in Germany [15]).

Insulin degludec (IDeg) is a new basal insulin (currently approved in Europe, Japan, Mexico and several other countries) with a flat, ultra-long action profile that may enable subjects to achieve glycosylated hemoglobin $\left(\mathrm{HbA}_{1 \mathrm{c}}\right)$ levels closer to glycemic target with fewer hypoglycemic episodes [19-21]. It was thus hypothesized that IDeg could be titrated once-weekly based on a single pre-breakfast SMBG value, offering a simple, patient-focused titration algorithm that would encourage self-titration, enhancing patient empowerment as well as substantially reducing treatment costs 
by reducing the frequency of blood glucose measurements required for dose adjustments. In this study, after 26 weeks of treatment, the authors compared the efficacy and safety of two different self-titration algorithms for IDeg administered once-daily (OD) plus metformin, in insulin-naïve subjects with type 2 diabetes: a "Simple" algorithm, in which 4 unit (U) dose adjustments were made based on a single pre-breakfast SMBG measurement was compared with a "Step-wise" algorithm, in which dose adjustments were made in increments of $2 \mathrm{U}$ (Table 1) based on the lowest of three consecutive pre-breakfast SMBG readings. In both groups, IDeg was adjusted once-weekly. The objective of this trial was to provide additional guidance on the use of IDeg in clinical practice by investigating whether good glycemic control could be attained with a more simplified titration schedule, involving fewer SMBG tests, than that previously employed during the IDeg Phase 3a development program.

Table 1 Comparison of BEGIN ${ }^{\circledR}$ Once Simple titration algorithms

\begin{tabular}{llll}
\hline \multicolumn{2}{l}{ Pre-breakfast SMBG } & $\begin{array}{l}\text { Dose } \\
\text { adjustment }\end{array}$ & $\begin{array}{l}\text { Dose } \\
\text { adjustment } \\
\text { IDeg Simple }\end{array}$ \\
\cline { 1 - 2 } $\mathbf{m m o l} / \mathbf{L}$ & $\mathbf{m g} / \mathbf{d L}$ & $\begin{array}{l}\text { IDeg Step-wise } \\
\text { U }\end{array}$ & U \\
\hline$<3.1$ & $<56$ & -4 & -4 \\
$3.1-3.9$ & $56-70$ & & -2 \\
$4.0-5.0$ & $71-90$ & 0 & 0 \\
$5.1-7.0$ & $91-126$ & +4 & +2 \\
$7.1-8.0$ & $127-144$ & & +4 \\
$8.1-9.0$ & $145-162$ & & +6 \\
$>9.0$ & $>162$ & & +8 \\
\hline
\end{tabular}

$I D e g$ insulin degludec, $S M B G$ self-measured blood glucose

${ }^{a}$ Based on a single measurement on the day of titration

b Based on the lowest of 3 consecutive days' measurements

\section{METHODS}

The study was conducted according to the Declaration of Helsinki, as revised in 2000 and 2008 [22] and ICH Good Clinical Practice (1996) guidelines [23], with prior approval by appropriate ethics committees and patient consent obtained in writing prior to the start of any study-related activities. Eligible participants included insulin-naïve men or women $\geq 18$ years of age, with type 2 diabetes, $\mathrm{HbA}_{1 \mathrm{c}}$ 7.0-10.0\% (inclusive), and body mass index (BMI) $\leq 45.0 \mathrm{~kg} / \mathrm{m}^{2}$, who were treated with $\geq 1,000 \mathrm{mg}$ /day metformin alone or in combination with one or two other oral antidiabetic medications (OADs) [including a sulfonylurea (SU) or Glinide, dipeptidyl peptidase-4 (DPP-4) inhibitors, $\alpha$-glucosidase inhibitors or thiazolidinediones (TZDs)], with unchanged dosing for $\geq 12$ weeks prior to randomization. Participants were ineligible if they had used a glucagon-like peptide-1 (GLP-1) receptor agonist within 12 weeks prior to randomization, had initiated or significantly changed treatment that could interfere with glucose metabolism, had significant disease other than type 2 diabetes, were pregnant or breastfeeding, or had recurrent severe hypoglycemia or hypoglycemia unawareness. Subjects could be withdrawn from the trial due to withdrawal of consent, not fulfilling inclusion/exclusion criteria (randomized in error), non-compliance, or at the discretion of the investigator due to a safety concern. Subjects who were withdrawn after randomization were not to be replaced.

\section{Study Design and Treatment}

This was a multinational (conducted in the US, Spain, Finland, and Germany), Phase $3 b$, multi-center, two-armed, parallel group, 
open-label, randomized, treat-to-target study that compared the efficacy and safety of IDeg OD (IDeg $100 \mathrm{U} / \mathrm{mL}$, FlexTouch ${ }^{\circledR}$ pen, Novo Nordisk A/S, Bagsværd, Denmark), adjusted using two different titration algorithms in combination with metformin. The trial consisted of a 26-week period; total study duration was $\sim 28$ weeks (including 1 week for screening and a 7-day follow-up period). After discontinuing all OADs other than metformin, subjects were randomized $1: 1$ by an interactive voice/web response system (IV/WRS) to IDeg $_{\text {Simple }}$ or IDeg Step-wise $_{\text {insulin self-titration }}$ algorithms, as defined below. Subjects were instructed to self-titrate in accordance with their respective algorithms and continue with their pre-trial metformin dose. At randomization, week 4 , and week 12 , subjects in both treatment arms received diet and exercise counselling by an HCP. The importance of maintaining a healthy diet and exercise plan was reinforced at each visit.

A Novo Nordisk A/S safety committee blinded to treatment performed on-going safety surveillance, but could request unblinding of the data to be performed by an independent ad hoc group, if needed. An external cardiovascular adjudication committee was masked to treatment. Blinded insulin titration surveillance was performed by Novo Nordisk A/S.

Insulin degludec was administered OD at a starting dose of $10 \mathrm{U}$ in both groups. Variation of injection time from day to day was permitted, as long as subjects maintained a minimum of 8 and a maximum of $40 \mathrm{~h}$ between injections. Self-adjustment of IDeg dose was to be performed once-weekly in both groups according to the algorithms outlined in Table 1. In the IDeg simple $_{\text {arm, dose adjustment }}$ was based on a single pre-breakfast SMBG measurement. In the IDeg $_{\text {Step-wise }}$ arm, dose adjustment was based on the lowest of 3 consecutive days' pre-breakfast SMBG measurements.

\section{Efficacy and Safety Assessments}

$\mathrm{HbA}_{1 \mathrm{c}}$ was analyzed using a Bio-Rad high-performance liquid chromatography method at Visits 1 (screening), 2 (randomization), 14 (week 12), and 28 (week 26). Fasting plasma glucose (FPG) blood samples were assayed using a hexokinase-UV method at Visits 2, 14, and 28. At the first visit, subjects were provided with a glucose meter for SMBG measurement and instructions for use; blood glucose was measured with test strips calibrated to plasma glucose (PG) to obtain PG-equivalent values presented in this report. Subjects performed SMBG measurements before breakfast weekly after randomization and also performed an 8-point SMBG profile prior to Visits 2, 14, and 28.

Adverse events (AEs) and hypoglycemic episodes were documented throughout the study, with confirmed hypoglycemia defined as episodes of severe hypoglycemia (requiring assistance from another person) and episodes with PG value $<3.1 \mathrm{mmol} / \mathrm{L} \quad(56 \mathrm{mg} / \mathrm{dL})$. Confirmed nocturnal hypoglycemic episodes were those occurring between 0001 and 0559 hours (inclusive). Laboratory safety variables, insulin dose, and body weight were recorded at pre-specified intervals. Two patient-reported outcome (PRO) questionnaires (Device-Specific questionnaires I and II) were self-completed at Visits 14 and 28 to assess subject satisfaction with the FlexTouch pen as an additional trial endpoint. The PRO questionnaire utilized here to assess patient satisfaction with FlexTouch had previously been used in other trials to assess satisfaction with the FlexPen ${ }^{\circledR}$ device (Novo Nordisk A/S, Bagsværd, Denmark) [24, 25]. 


\section{Statistical Methods}

With 218 subjects, there was $85 \%$ power to demonstrate non-inferiority at $0.4 \%$ in evaluation of the per-protocol (PP) analysis set (defined as all subjects without major protocol violations who were exposed to treatment for $>12$ weeks and who had a valid assessment necessary for deriving the primary endpoint), accounting for an anticipated total of $15 \%$ that would not be included in the PP analysis set. Sample size was determined using a $t$-statistic under the assumption of a one-sided test of size $2.5 \%$ and a zero mean treatment difference. Data were reported using a 95\% CI and $P$ values for one-sided testing for non-inferiority at alpha $=0.025$ for the primary analysis, and two-sided testing with alpha $=0.050$ for all other analyses. Statistical analyses of all efficacy and patient-reported outcome endpoints were based on the full analysis set (FAS), defined as all randomized subjects, and followed the intention-to-treat (ITT) principle unless otherwise noted. The robustness of the results for change in $\mathrm{HbA}_{1 \mathrm{c}}$ was explored by an additional analysis of the PP analysis set. Further, robustness was explored by an additional analysis of the set of all subjects who completed the trial and by using a simple model based on the FAS with only treatment and baseline $\mathrm{HbA}_{1 \mathrm{c}}$ as covariates. Safety endpoints were summarized based on the safety analysis set (SAS), defined as all subjects who received at least one dose of IDeg, and analyzed based on the FAS. Statistical analyses were performed using $\mathrm{SAS}^{\circledR}$ 9.1.3 software (SAS Institute Inc., Cary, NC, USA).

Change from baseline in $\mathrm{HbA}_{1 \mathrm{c}}$ after 26 weeks was analyzed using an analysis of variance (ANOVA) method with treatment, region, sex, and antidiabetic therapy at screening as fixed factors, and age and baseline
$\mathrm{HbA}_{1 \mathrm{c}}$ as covariates. Non-inferiority was considered confirmed if the upper bound of the two-sided 95\% CI for the treatment difference (IDeg Simple $_{-}$IDeg $_{\text {Step-wise }}$ ) for the mean change in $\mathrm{HbA}_{1 \mathrm{c}}$ was $\leq 0.4 \%$. Change in FPG and change in body weight were analyzed using an ANOVA model similar to that used for the primary analysis, but with the relevant baseline value as covariate for each measure. Responder endpoints (proportion of subjects who achieved target $\mathrm{HbA}_{1 \mathrm{c}}$ and proportion who achieved target without hypoglycemia) were analyzed using a logistic regression model with the same factors and covariates as those used for the primary analysis. An 8-point SMBG profile included measurements before and $90 \mathrm{~min}$ after the start of breakfast, lunch and main evening meal, prior to bedtime, and before breakfast the following day. A mixed effect model including treatment, time, interaction between treatment and time, antidiabetic therapy at screening, sex and region as fixed factors, age as covariate and subject as random effect was fitted to the 8-point SMBG profile data. From this model, mean profile by treatment and relevant treatment differences were estimated and explored. Treatment-emergent AEs, hypoglycemic episodes, laboratory parameters, physical examination, electrocardiogram (ECG), fundoscopy/fundusphotography, vital signs, PRO (Device-Specific questionnaires I and II) and insulin dose were summarized with descriptive statistics. The numbers of treatment-emergent confirmed and nocturnal confirmed hypoglycemic episodes were analyzed using a negative binomial regression model with a log-link function and the logarithm of the time period for which a hypoglycemic episode was considered treatment emergent as offset; the model included treatment, sex, region, and 
Table 2 Demographics and baseline characteristics

\begin{tabular}{|c|c|c|}
\hline Characteristic & $\begin{array}{l}\text { IDeg } \\
\text { Simple }\end{array}$ & $\begin{array}{l}\text { IDeg } \\
\text { Step-wise }\end{array}$ \\
\hline $\begin{array}{l}\text { Participants in the } \\
\text { full analysis set, } n\end{array}$ & 111 & 111 \\
\hline $\begin{array}{l}\text { Participants in the } \\
\text { safety analysis } \\
\text { set, } n\end{array}$ & 110 & 111 \\
\hline $\begin{array}{l}\text { Female/male, } \\
n(\%)\end{array}$ & $\begin{array}{l}43(38.7) / 68 \\
(61.3)\end{array}$ & $\begin{array}{l}36(32.4) / 75 \\
(67.6)\end{array}$ \\
\hline $\begin{array}{l}\text { Ethnic group: } \\
\text { White/Black/ } \\
\text { Asian, American } \\
\text { Indian or Alaska } \\
\text { native/other, } \\
n(\%)\end{array}$ & $\begin{array}{l}99(89.2) / 8 \\
(7.2) / 3 \\
(2.7) / 1(0.9)\end{array}$ & $\begin{array}{l}97(87.4) / 9 \\
(8.1) / 2 \\
(1.8) / 3(2.7)\end{array}$ \\
\hline Age (years) & $59.4( \pm 9.5)$ & $58.5( \pm 11.1)$ \\
\hline Body weight (kg) & $95.7( \pm 18.9)$ & $91.3( \pm 18.2)$ \\
\hline $\begin{array}{l}\text { Body mass index } \\
\left(\mathrm{kg} / \mathrm{m}^{2}\right)\end{array}$ & $33.4( \pm 5.8)$ & $31.5( \pm 5.2)$ \\
\hline $\begin{array}{l}\text { Duration of } \\
\text { diabetes (years) }\end{array}$ & $8.9( \pm 5.5)$ & $9.6( \pm 7.2)$ \\
\hline $\mathrm{HbA}_{1 \mathrm{c}}(\%)$ & $8.1( \pm 0.9)$ & $8.2( \pm 0.9)$ \\
\hline \multicolumn{3}{|l|}{ FPG } \\
\hline $\mathrm{mmol} / \mathrm{L}$ & $9.3( \pm 2.6)$ & $9.4( \pm 2.8)$ \\
\hline $\mathrm{mg} / \mathrm{dL}$ & $167.4( \pm 46.8)$ & $169.2( \pm 50.4)$ \\
\hline \multicolumn{3}{|l|}{$\begin{array}{l}\text { OAD treatment at } \\
\text { screening, } n(\%)\end{array}$} \\
\hline $1 \mathrm{OAD}$ & $27(24.3)$ & $26(23.4)$ \\
\hline Met & $27(24.3)$ & $26(23.4)$ \\
\hline 2 OADs & $61(55.0)$ & $61(55.0)$ \\
\hline Met + DPP-4I & $16(14.4)$ & $13(11.7)$ \\
\hline Met + Glinide & $1(0.9)$ & $2(1.8)$ \\
\hline $\mathrm{Met}+\mathrm{SU}$ & $40(36.0)$ & $42(37.8)$ \\
\hline Met + TZD & $4(3.6)$ & $4(3.6)$ \\
\hline
\end{tabular}

Table 2 continued

\begin{tabular}{lcc}
\hline Characteristic & $\begin{array}{l}\text { IDeg } \\
\text { Simple }\end{array}$ & $\begin{array}{l}\text { IDeg } \\
\text { Step-wise }\end{array}$ \\
\hline 3 OADs & $23(20.7)$ & $24(21.6)$ \\
$\begin{array}{l}\alpha \text {-glu inhib + Met + } \\
\text { DPP-4I }\end{array}$ & $1(0.9)$ & - \\
Met + DPP-4I + & $1(0.9)$ & $3(2.7)$ \\
Glinide & & \\
Met + DPP-4I + SU & $13(11.7)$ & $8(7.2)$ \\
Met + DPP-4I + TZD & - & $2(1.8)$ \\
Met + SU + TZD & $8(7.2)$ & $11(9.9)$ \\
\hline
\end{tabular}

Data are presented as number (\%) or mean (SD)

$O A D$ oral antidiabetic drug, $M e t$ metformin, $S U$ sulfonylurea, $T Z D$ thiazolidinedione, DPP-4I dipeptidyl peptidase 4 inhibitor, $\alpha$-glu inhib, alpha-glucosidase inhibitor, $F P G$ fasting plasma glucose, $I D e g$ insulin degludec, $S D$ standard deviation, $H b A_{1 c}$ glycosylated hemoglobin

antidiabetic treatment at screening as fixed factors and age as covariate.

\section{RESULTS}

Participants were allocated 1:1 to the IDeg Simple $_{\text {I }}$ $(n=111)$ and IDeg $_{\text {Step-wise }}(n=111)$ arms (Table 2). Of 222 randomized participants, 221 (99.5\%) received trial drug. Treatment arms were well matched at baseline, with the exception of a slightly higher mean body weight and more female subjects in the IDeg $_{\text {simple }}$ arm. The majority of subjects were white [89.2\% (IDeg Simple $)$ and 87.4\% (IDeg Step-wise $)$. Subjects in the IDeg Step-wise $_{\text {arm had a slightly }}$ longer mean duration of diabetes. The majority of participants in both groups were taking two OADs at baseline (61/111 subjects, 55\%); 21\% in each group were taking $>2$ OADs, and $\sim 24 \%$ in each group were taking $1 \mathrm{OAD}$. The most 
common pre-trial OAD other than metformin was a SU. Most [89.2\% (99/111), IDeg Simple; $88.3 \% \quad(98 / 111), \quad$ IDeg $\left._{\text {Step-wise }}\right]$ subjects completed the trial. Four IDegsimple and three IDeg $_{\text {Step-wise }}$ subjects were withdrawn due to AEs; five IDeg Simple $_{\text {and seven }}$ IDeg $_{\text {Step-wise }}$ subjects were withdrawn due to meeting withdrawal criteria; and three subjects in each group were withdrawn due to reasons classified as "other" (Fig. 1).

$\mathrm{HbA}_{1 \mathrm{c}}$ decreased from baseline to week 26 in both groups; $-1.09 \%$ with IDeg $_{\text {Simple, }}$ to $7.0 \%$, and $-0.93 \%$ with IDeg Step-wise, $_{\text {to }} 7.2 \%$ (Fig. 2a). IDeg $_{\text {simple }}$ was non-inferior to IDeg Step-wise in lowering $\mathrm{HbA}_{1 \mathrm{c}}$, as the upper limit of the $95 \%$ CI for the estimated treatment difference (ETD) was $<0.4 \%$ : ETD $\quad$ (IDeg $_{\text {Simple }}-$ IDeg $\left._{\text {Step-wise }}\right)$ $-0.16 \%$-points $(-0.39 ; 0.07)_{95 \% \mathrm{CI}}$. Analyses to measure robustness of results were consistent with FAS results. Significantly more IDeg $_{\text {Simple }}$ $[56.8 \%(63 / 111)]$ than IDeg $_{\text {Step-wise }}[41.4 \%$ (46/111)] subjects achieved $\mathrm{HbA}_{1 \mathrm{c}}<7.0 \%$ at end-of-trial; estimated odds ratio (IDeg Simple $_{\text {IDeg }}$ Step-wise): $1.93(1.04 ; 3.55)_{95 \% ~ C I}$ $(P=0.0356)$. There was no significant difference in the proportion of patients achieving $\mathrm{HbA}_{1 \mathrm{c}}$ $<7 \%$ without confirmed hypoglycemia [40.6\%

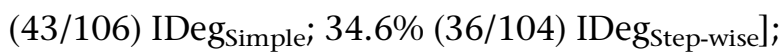
estimated odds ratio (IDeg Simple $_{\text {IDeg }} /$ Step-wise $)$ : $1.26(0.69 ; 2.29)_{95 \% \mathrm{CI}}$.

Fasting plasma glucose decreased from baseline to week 26 by $3.27 \mathrm{mmol} / \mathrm{L}$ with IDeg $_{\text {Simple, }}$ to $6.1 \mathrm{mmol} / \mathrm{L}$, and by $2.68 \mathrm{mmol} / \mathrm{L}$ with IDeg $_{\text {Step-wise, to }} 6.8 \mathrm{mmol} / \mathrm{L}$ (Fig. 2b). No significant difference was seen between groups: ETD $\quad\left(\right.$ IDeg $_{\text {Simple }}-$ IDeg $_{\text {Step-wise: }}-0.57 \mathrm{mmol} / \mathrm{L}$ $(-1.30 ; 0.17)_{95 \%}$ CI. The most pronounced decline in FPG occurred during the first 12 weeks. No difference between groups in 8-point SMBG profiles was seen at any of the eight measured time points at baseline or at end-of-trial (Fig. 2c).
Rates of confirmed hypoglycemia were low, at 1.60 and 1.17 events per patient year of exposure (PYE) with IDeg Simple $_{\text {and IDeg }}$ Step-wise, respectively (Fig. 3a), with no significant difference between groups $(P=0.4273)$. One severe hypoglycemic episode occurred in the IDeg $_{\text {Simple }}$ arm 5 days after the last treatment with IDeg. Observed rates of nocturnal confirmed hypoglycemia were very low at 0.21 (IDeg Simple $)$ and 0.10 (IDeg $\left._{\text {Step-wise }}\right)$ events per PYE (Fig. 3b), with no significant difference between groups $(P=0.2047)$.

The observed daily insulin dose after 26 weeks was $62 \mathrm{U}(0.61 \mathrm{U} / \mathrm{kg})$ in the IDeg $_{\text {Simple }}$ arm and $48 \mathrm{U}(0.50 \mathrm{U} / \mathrm{kg})$ in the IDeg $_{\text {Step-wise }}$ arm. Up to week 4, mean doses were similar, after which the mean dose in the Simple arm was higher. The increase in IDeg dose per week began to level off in the IDeg Step-wise $_{\text {se }}$ arm at week 14 . Although subjects were permitted to adjust their dose by increments larger than $4 \mathrm{U}$ in the IDeg $_{\text {Step-wise }}$ arm, the mean weekly incremental increase was $\leq 3 \mathrm{U}$.

Mean baseline body weight was higher in the IDeg $_{\text {Simple }}$ arm $(95.7 \mathrm{~kg})$ than in the IDeg $_{\text {Step-wise }}$ arm $(91.3 \mathrm{~kg})$. Modest increases in weight were observed from baseline to week 26 in both

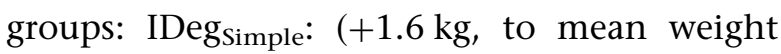
$97.3 \mathrm{~kg}$ at week 26), IDeg ${ }_{\text {Step-wise }}(+1.1 \mathrm{~kg}$, to mean weight $92.4 \mathrm{~kg}$ at week 26), with no statistically significant difference in weight change: ETD (IDeg Simple $_{\text {- IDeg }}$ Step-wise) $0.46 \mathrm{~kg}$

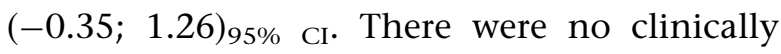
relevant differences from baseline to end-of-trial or between treatment arms in vital signs, ECG, fundoscopy, physical examination or laboratory parameters (data not shown).

No safety concerns were raised during this trial. Please see Table 3 for an overview of the rates of AEs and serious AEs (SAEs) reported. AEs and SAEs were distributed similarly between groups. Most AEs were of mild or moderate 


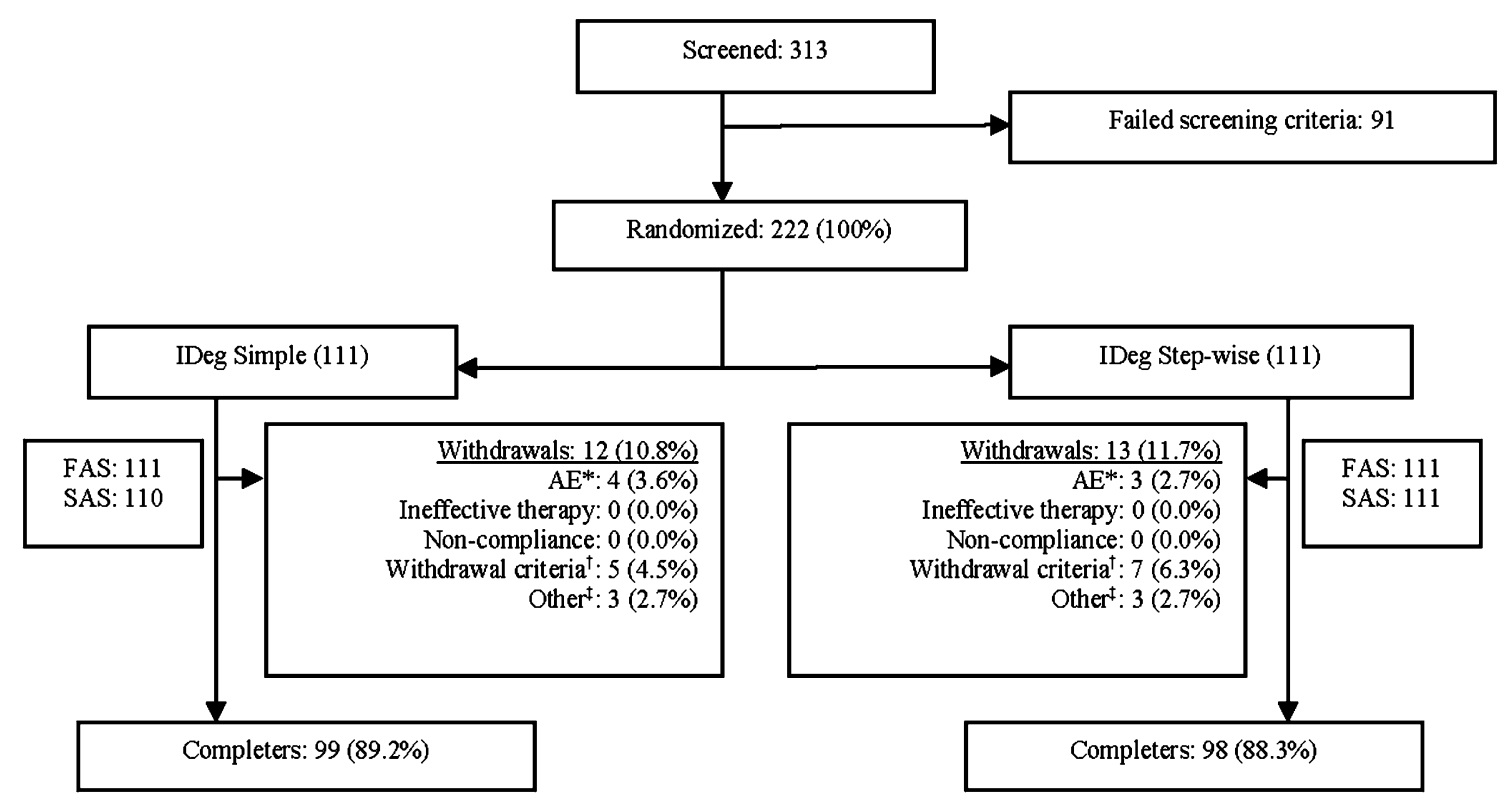

Fig. 1 BEGIN Once Simple participant flow. ${ }^{*} \mathrm{IDeg}_{\text {Simple: }}$ arthralgia and blurred vision (1 subject); toxicity to various agents ( 1 subject); astrocytoma ( 1 subject); acute myocardial infarction (1 subject). IDeg Step-wise: liver metastases

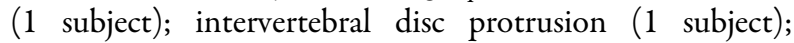
worsening of type 2 diabetes/vitamin D deficiency/anterior pituitary disorder/depression (1 subject). ${ }^{\dagger} \mathrm{IDeg}_{\text {Simple: }}$ : withdrawal of consent (2 subjects), investigator decision to withdraw subject due to safety or non-compliance

(2 subjects), randomized in error ( 1 subject). IDeg $_{\text {Step-wise: }}$ withdrawal of consent ( 2 subjects), investigator decision to withdraw subject due to safety or non-compliance (1 subject), randomized in error (4 subjects). ${ }^{*} \mathrm{IDeg}_{\text {Simple }}$ lost to follow-up (2 subjects) and withdrawn after 11.7 weeks of treatment due to $\mathrm{HbA}_{1 \mathrm{c}}$ increased $\left(1\right.$ subject) IDeg $\mathrm{I}_{\text {Step-wise: }}$ lost to follow-up (3 subjects). $A E$ adverse event, $F A S$ full analysis set, $I D e g$ insulin degludec, $S A S$ safety analysis set

severity and the rates of AEs classified as possibly or probably related to trial product by the investigator were low $\left[10.0 \%\right.$ (IDeg $\left._{\text {Simple }}\right)$; $7.2 \%$ (IDeg Step-wise $)$. Injection-site reactions (ISRs) were reported by $2.7 \%$ (3 subjects with 3 events) of IDeg Simple $_{\text {and }} 4.5 \%$ (5 subjects with 16 events) of IDeg Step-wise $_{\text {subjects; one subject }}$ reported 9 of the 16 total events in the IDeg Step-wise $_{\text {. }}$ arm, and reported "pain" as the ninth ISR. NoSAEs were reported in $\geq 5 \%$ of subjects and none were considered by the investigator to be related to trial product. One death occurred in this study 154 days after starting trial drug in an IDeg $_{\text {Step-wise-treated participant, due to liver }}$ metastasis (the primary cancer was reported as probable small cell lung carcinoma). The event was considered by the investigator to be unlikely

related to treatment. One other SAE neoplasm event [astrocytoma (IDeg Simple $)$, and three events adjudicated as major adverse cardiovascular events [coronary artery stenosis (IDeg Simple), ) acute myocardial infarction (IDeg Simple $_{\text {) and }}$ coronary artery occlusion (IDeg Step-wise $_{\text {) }}$ ] occurred, all of which were considered by the investigator to be unlikely related to treatment. No IDeg-related medication errors were reported.

In the Device-Specific questionnaires, designed to assess satisfaction with the insulin delivery device, more than $90 \%$ of subjects at week 12 and week 26 indicated the highest levels of satisfaction (response category 1 or 2 ) with FlexTouch in categories such as confidence in using the pen, ease in learning to use the device, ease in holding the pen stable or seeing 

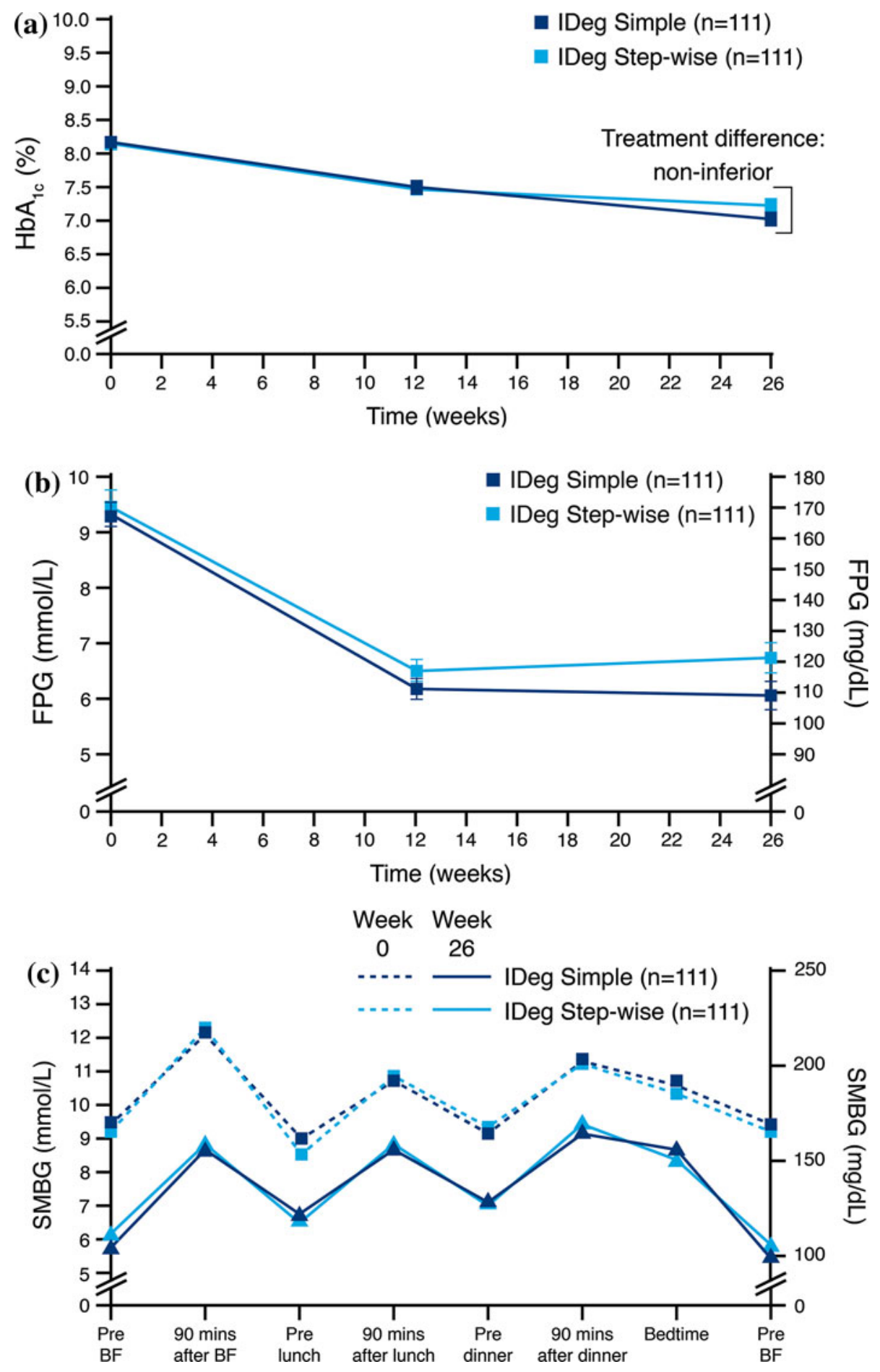

Fig. 2 BEGIN Once Simple glycemic efficacy: a mean $\mathrm{HbA}_{1 \mathrm{c}}$ over time; $\mathbf{b}$ mean FPG \pm SEM over time; IDeg insulin degludec, $H b A_{\text {Ic }}$ glycosylated hemoglobin, c 8-point SMBG profile at baseline and week 26. $B F$ breakfast, $F A S$ full analysis set, $F P G$ fasting plasma glucose, $S E M$ standard error of the mean, $S M B G$ self-measured blood glucose 
the dose scale while injecting, pushing down the injection button and selecting the correct dose. At 26 weeks, $98 \%$ of subjects reported no
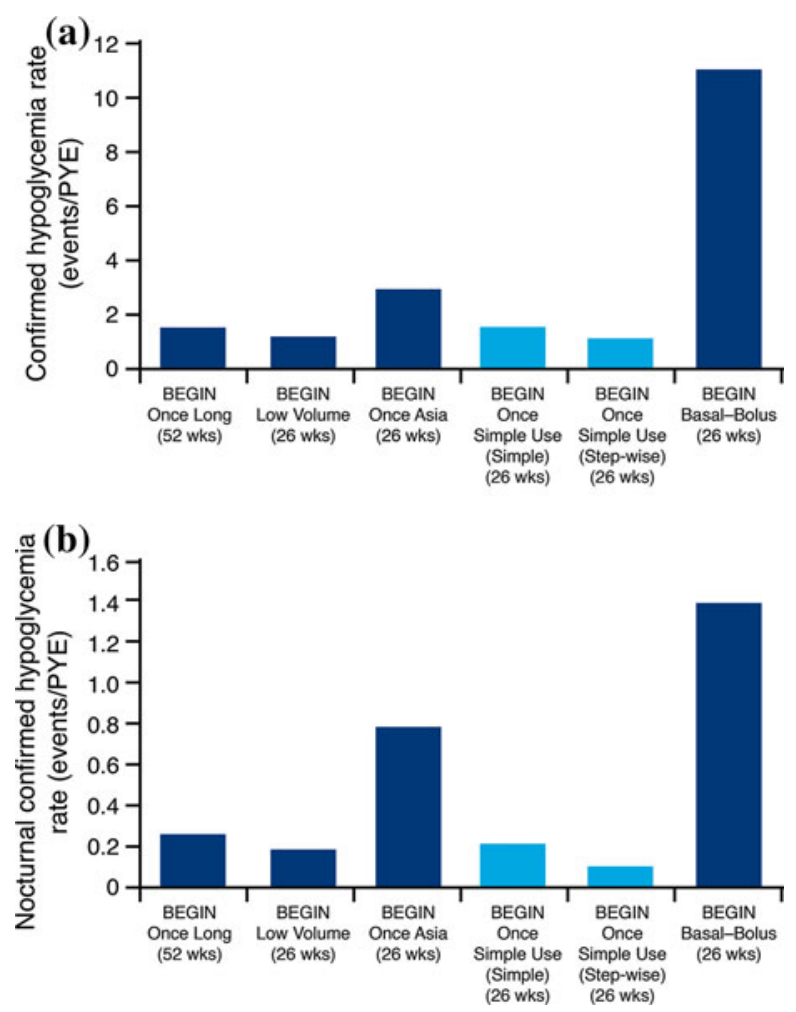

Fig. 3 Hypoglycemia rate (IDeg) in the BEGIN Type 2 diabetes trials: a confirmed hypoglycemia, $\mathbf{b}$ nocturnal confirmed hypoglycemia. Data from this trial shown by light blue bars. Rate (events/patient year of exposure) is at end-of-trial and based on SAS. IDeg insulin degludec, PYE patient year of exposure, $S A S$ statistical analysis set problems using FlexTouch and $100 \%$ of subjects indicated that they would recommend the pen. Please refer to Table 4 for additional details on the results of the questionnaires (Table 4 contains a subset of the total questions surveyed in this trial).

\section{DISCUSSION}

Both the Simple and Step-wise titration algorithms were effective, well-tolerated methods of achieving glycemic targets with IDeg, thereby demonstrating that titration based on either a single weekly SMBG measurement with the Simple algorithm, or three measurements with the Step-wise algorithm, provide suitable options for patients with type 2 diabetes. Titration using the Simple algorithm was shown to be non-inferior to titration using the Step-wise algorithm in terms of improving $\mathrm{HbA}_{1 \mathrm{c}}$ and both methods resulted in a similar FPG reduction. End-of-trial $\mathrm{HbA}_{1 \mathrm{c}}$ and change from baseline in $\mathrm{HbA}_{1 \mathrm{c}}$ in both treatment arms were similar to values seen with IDeg in similar previous Phase 3a (BEGIN) trials in people with type 2 diabetes [26-29]. These previous trials all demonstrated similar efficacy between

Table 3 Summary of adverse events

\begin{tabular}{|c|c|c|c|c|c|c|c|c|}
\hline & \multicolumn{4}{|c|}{ IDeg Simple $(n=110)$} & \multicolumn{4}{|c|}{ IDeg Step-wise $(n=111)$} \\
\hline & $\bar{n}$ & $\%$ & $\boldsymbol{E}$ & $\boldsymbol{R}$ & $\bar{n}$ & $\%$ & $\boldsymbol{E}$ & $\boldsymbol{R}$ \\
\hline AEs & 66 & 60.0 & 181 & 346 & 69 & 62.2 & 197 & 379 \\
\hline AEs occurring with a frequency $\geq 5 \%$ & 17 & 15.5 & 18 & 34 & 14 & 12.6 & 22 & 42 \\
\hline Headache & 8 & 7.3 & 8 & 15 & 8 & 7.2 & 14 & 27 \\
\hline Nasopharyngitis & 10 & 9.1 & 10 & 19 & 7 & 6.3 & 8 & 15 \\
\hline SAEs & 5 & 4.5 & 8 & 15 & 7 & 6.3 & 8 & 15 \\
\hline
\end{tabular}

Treatment-emergent events occurring after first exposure and no later than 7 days after last exposure. Safety analysis set. $n$ number of patients with events, $\%$ proportion of patients with events, $E$ number of events, $R$ number of events per 100 patient-years 
Table 4 Device-Specific questionnaire responses

$\begin{array}{ll}\begin{array}{l}\text { Positive response } \\ (\text { Category 1 or 2) }\end{array} & \begin{array}{l}\text { Neutral or negative } \\ \text { response (Category 3, } \\ 4 \text { or 5) }\end{array} \\ n(\%) & n(\%)\end{array}$

1. How easy or difficult do you find it to hold the pen stable when injecting?
Wk $12195(94.7)$
Wk $26202(98.5)$

2. How easy or difficult is it to push down the injection button?
Wk $12197(95.2)$
Wk $26202(98.0)$

3. How easy or difficult is it to turn the dose selector when choosing the right dose?
Wk $12199(97.5)$
Wk $26196(96.1)$

4. How easy or difficult is it to know if the push button has been pushed down completely?
Wk $12192(93.2)$
$14(6.8)$
Wk $26195(95.2)$
$9(4.8)$

5. How easy or difficult is it to see the dose scale when injecting?

Wk $12176(85.5)$

$30(14.5)$

Wk $26 \quad 174(85.2)$

$30(14.8)$

6. How easy or difficult was it to learn how to use this pen?
Wk $12200(98.0)$
$4(2.0)$
Wk $26199(98.5)$
$3(1.5)$

7. How easy or difficult is it to inject your usual insulin dose?

Wk $12193(94.6)$

$11(5.4)$

Wk $26196(97.0)$

$6(3.0)$

8 . How easy or difficult is it to reach the dose button when injecting your insulin dose?
Wk $12193(94.6)$
$11(5.4)$
Wk $26195(96.5)$
$7(3.5)$

Table 4 continued

\begin{tabular}{ll}
\hline $\begin{array}{l}\text { Positive response } \\
(\text { Category 1 or 2) }\end{array}$ & $\begin{array}{l}\text { Neutral or negative } \\
\text { response (Category 3, } \\
4 \text { or 5) } \\
n(\%)\end{array}$ \\
$n(\%)$ & \begin{tabular}{l} 
a \\
\hline
\end{tabular}
\end{tabular}

9. Overall, how confident are you in your management of daily insulin injection using this pen?
Wk $12191(93.1)$
$14(6.9)$
Wk $26196(96.1)$
$8(3.9)$

10. Overall, how confident are you in controlling your blood sugar level using this pen?
Wk $12 \quad 167$ (81.8)
$37(18.2)$
Wk $26 \quad 178(88.6)$
$23(11.4)$

\begin{tabular}{ll}
\hline $\begin{array}{l}\text { Positive response } \\
n(\%)\end{array}$ & $\begin{array}{l}\text { Negative response } \\
n(\%)\end{array}$ \\
\hline
\end{tabular}

1. Did you have any problems using the pen?

$\begin{array}{lll}\text { Wk } 12 & 205(100.0) & \text { N/A } \\ \text { Wk } 26 & 201(100.0) & \text { N/A }\end{array}$

2. Would you recommend the pen?

$\begin{array}{lll}\text { Wk } 12 & 202(100.0) & \text { N/A } \\ \text { Wk 26 } & 200(100.0) & \text { N/A }\end{array}$

${ }^{a}$ Data is based on FAS and summarized independent of treatment arm. \% percentage based on ITT population who answered the questionnaire. Categories for questions 1-8: 1 very easy, 2 somewhat easy, 3 neither easy nor difficult, 4 somewhat difficult, 5 very difficult. Categories for questions 9-10: 1 very, 2 quite, 3 somewhat, 4 not very, 5 not at all (confident). $N$ number, $W k$ week, ITT intention-to-treat

b Data is based on FAS and summarized independent of treatment arm. Categories for questions 1-2: 1 no, 2 yes. $N$ number, $W k$ week, $N A$ not applicable, ITT intentionto-treat

IDeg and insulin glargine as demonstrated by non-inferiority in terms of change in $\mathrm{HbA}_{1 \mathrm{c}}$, were 26 or 52 weeks in duration, enrolled insulin-naïve subjects (except for the BEGIN Basal-Bolus T2 study in which insulin aspart 
was dosed with meals [26]) and employed a titration algorithm similar to the Step-wise algorithm, but with weekly titration based on the mean of three consecutive days' pre-breakfast SMBG measurements [26-29].

IDeg dose was increased more quickly in the IDeg Simple arm, whereas insulin dose escalation was reduced earlier in the IDeg $_{\text {Step-wise }}$ arm, reflecting a point of differentiation between the algorithms: as pre-breakfast SMBG values approached target, the Step-wise algorithm permitted a smaller dose increase of $2 \mathrm{U}$ versus the recommended $4 \mathrm{U}$ increase in

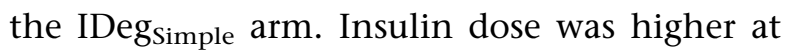

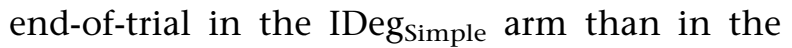
IDeg $_{\text {Step-wise }}$ arm, which may account for the non-significant differences seen between groups in FPG and hypoglycemia. FPG values were numerically lower over longer periods of time in the IDeg Simple arm; this may have influenced the observed rates of hypoglycemia, as these rates represented the entire treatment period. The small and non-significant difference in FPG between the IDeg SSimple $_{\text {and }}$ IDeg $_{\text {Step-wise }}$ arms likely also contributed to the difference between groups in achieving the $\mathrm{HbA}_{1 \mathrm{c}}$ target of $<7 \%$. It is important to note that there was no significant difference between groups in the achievement of the $\mathrm{HbA}_{1 \mathrm{c}}$ target without confirmed hypoglycemia.

The Simple algorithm offers an easy and patient-friendly way to titrate IDeg; in addition, the capacity to adjust IDeg doses with a $4 \mathrm{U}$ increase or decrease, based on a single weekly SMBG value, may substantially reduce the financial and time burden and inconvenience of titration measurements. Incidence rates of hypoglycemic episodes were very low, with no significant difference between the Simple and Step-wise arms. As shown in Fig. 3a and b, respectively, end-of-trial confirmed and nocturnal confirmed hypoglycemia rates seen here were comparable to or lower than rates with IDeg administered OD in the BEGIN trials in people with type 2 diabetes; rates that, in turn, were lower than or similar to those seen with comparator insulin glargine in other studies of the insulin degludec development program [26-29].

Subjects in both treatment arms adhered closely to their respective algorithms. The ability and willingness of patients to adhere to a given treatment regimen is an important component in the success of insulin therapy. Surveys of physicians and patients have identified "too busy" and "complicated regimen" as prominent reasons why patients miss or omit insulin injections; $17 \%$ of patients report difficulty in adjusting insulin doses, and $60 \%$ of patients feel that their insulin regimens can be restrictive $[10,11]$. There is evidence to support the premise that if patients are more comfortable with, and accepting of, their dosing regimen, they may be more willing to continue treatment in the long-term [12-14]. Furthermore, patient empowerment may be enhanced by a titration algorithm that facilitates self-adjustment of basal insulin and better adherence to treatment regimens, potentially leading to improved health outcomes. In the Predictable Results and Experience in Diabetes through Intensification and Control to Target: An International Variability Evaluation (PREDICTIVE) 303 study with insulin detemir [4], a simplified self-adjusted dosing algorithm in which patients tested SMBG daily and adjusted their dose every 3 days based on the mean of the previous 3 days' values was shown to significantly lower $\mathrm{HbA}_{1 \mathrm{c}}$ versus standard-of-care, physician-driven adjustments over a period of 6 months [4], thus, providing further evidence that a simple self-titration method can help subjects achieve glycemic targets. The efficacy 
and safety of insulin self-titration has likewise been demonstrated with additional studies with insulin detemir [30] and with insulin glargine [31-33], in which subjects experienced reductions in $\mathrm{HbA}_{1 \mathrm{c}}$ with a good safety profile when self-adjusting doses using trial-specified algorithms. In addition, patient acceptance of the insulin delivery device used to administer doses is a factor that appears to influence adherence and persistence with a given treatment regimen [34-37]. It has been reported that positive perceptions of convenience also play an important role in the persistence of pen use [38]. In this trial, although it was not designed to compare methods of insulin administration, high levels of satisfaction with the FlexTouch insulin pen device were reported in both treatment arms and all subjects indicated that they would recommend the pen to others. This reflects the experiences of patients in other IDeg trials using the same device, in which the majority of patients reported ease in using the pen and a high degree of satisfaction with FlexTouch [39-43].

In this study, insulin degludec was used in both arms of the trial. The effectiveness and safety of the two titration algorithms used with insulin degludec may not apply to treatment and decision-making with other basal insulins. This could represent a limitation of the study. Moreover, the open-label nature of the study could impact the results. Patients using the Simple algorithm may have found this algorithm easier to use. However, as patients in both arms adhered very closely to their treatment algorithms and efficacy and safety in both arms were comparable, there was no evidence to support that this potential bias impacted results. A longer-term study further exploring the Simple algorithm may be useful to determine the impact, if any, of a simpler titration algorithm on patient adherence to treatment and, ultimately, efficacy and safety outcomes.

\section{CONCLUSION}

Achieving good glycemic control in patients with type 2 diabetes is an important way to prevent or limit diabetes complications, and control the costs of intensified healthcare utilization stemming from these complications. SMBG is an integral part of effective diabetes management; however, glucose meters, test strips, lancets, and alcohol wipes are consumable items that comprise on-going expenses, with test strips identified as a major driver of these costs [15-18]. New medications and treatment regimens that permit a reduction in the number of SMBG measurements without compromising clinical outcomes would likely benefit all basal insulin-treated patients who may find current algorithms confusing or cumbersome. These patients may be more likely to adhere to a simpler regimen that ultimately results in improved health outcomes and lower healthcare costs. This trial demonstrates that IDeg, titrated using either the Simple or Step-wise algorithm, leads to good glycemic control and is well tolerated, offering individualized titration regimens that best meet patient needs.

\section{ACKNOWLEDGMENTS}

The study and article publication charge were sponsored by Novo Nordisk A/S (Bagsværd, Denmark). The authors thank the investigators, trial staff, and participants for their participation. The authors also thank Lisa Bonk, PharmD, MBA and Carolynne Van 
Houten, employees of Novo Nordisk, Inc., Princeton, NJ, USA, for providing medical writing and editorial assistance, and colleagues at Watermeadow Medical (sponsored by Novo Nordisk A/S) for copy editing, preparation of artwork, and submission assistance.

This full article has not been previously published nor is it currently submitted for consideration for publication elsewhere.

All authors contributed to design, conduct/data collection, analysis and interpretation of data and to the writing and final approval of this article.

Dr. Philis-Tsimikas is the guarantor for this article, and takes responsibility for the integrity of the work as a whole.

List of investigators. Finland: Arto Kuusisto, Vesa Järveläinen; Liisa Sorakivi, Sakari Sulosaari, Anne-Mari Helkkula; Germany: Thomas Behnke, Ralf Jordan, Karsten Milek, Rainer Paulus, Ludger Rose, Armin Sammler; Spain: Pedro Mezquita, Miguel Ángel Garcia, Santiago Tofé, Josefina Olivares, Esteban Jódar, Francisco Tinahones; USA: Alexander Murray, Marcus Merriweather, Dave Webster, Gary Bedel, Ileana Tandron, Jack Wahlen, Jeffrey Rothman, Jonathan Liss, Joshua Frame, Justen Rudolph, Michael Cooperman, Mohammed Bari, Norman Soler, Raul Gaona, Hubert Reyes and Steven Elliott, Elise Kwon, Teresa Sligh, Rakesh Patel, Ronald Gilman, Lon Lynn, David Deatkine, Athena Philis-Tsimikas, Joseph Risser, Peter Winkle, Saadat Ansari, Richard L. Murphy.

Conflict of interest. Athena Philis-Tsimikas has attended advisory boards for Novo Nordisk, Sanofi-Aventis and Merck and received research/education support from Takeda, Sankyo, Merck, Novo Nordisk, Sanofi-Aventis, Lilly, Amylin, Astra Zeneca and Pfizer. Meryl Brod has acted as a consultant to Forest Laboratories, Abbvie, Merck, Genentech and
Novo Nordisk. Marcus Niemeyer is an employee of Novo Nordisk. Ann Marie Ocampo Francisco is an employee of Novo Nordisk and holds stock in the company. Jeffrey Rothman has received clinical trials support from Amylin (now Bristol-Myers-Squibb), Boehringer-Ingelheim, Intarcia, GSK, Merck, Novo Nordisk, NPS Pharmaceuticals, and Sanofi-Aventis; attended speakers' bureaus for Boehringer-Ingelheim, Bristol-Myers-Squibb, Lilly, Sanofi-Aventis, Takeda; and acted as a consultant for NPS Pharmaceuticals, Takeda and Novo Nordisk.

Compliance with ethics guidelines. The study was conducted according to the Helsinki Declaration of 1975, as revised in 2000 and 2008 and ICH Good Clinical Practice (1996) guidelines, with prior approval by appropriate ethics committees and patient consent obtained in writing prior to the start of any study-related activities.

\section{REFERENCES}

1. American Diabetes Association. Standards of Medical Care in Diabetes-2012. Diabetes Care. 2012;35:S11-63.

2. International Diabetes Federation Clinical Guidelines Task Force. Global Guideline for Type 2 Diabetes. 2005. http://www.idf.org/webdata/docs/ IDF\%20GGT2D.pdf (Accessed 19 Dec 2012).

3. Canadian Diabetes Association Clinical Practice Guidelines Expert Committee. Canadian Diabetes Association. Can J Diabetes. 2008;32:S1-201.

4. Meneghini L, Koenen C, Wenig W, Selam J-L. The usage of a simplified self-titration dosing guideline (303 Algorithm) for insulin detemir in patients with type 2 diabetes-results of the randomized, controlled PREDICTIVE 303 study. Diabetes Obes Metab. 2007;9:902-13.

5. Davies M, Storms F, Shutler S, Bianchi-Biscay M, Gomis R. Improvement of glycemic control in subjects with poorly controlled type 2 diabetes. Diabetes Care. 2005;28:1282-8. 
6. LANTUS $^{\circledR}$ [insulin glargine (rDNA origin) injection]. Sanofi-aventis U.S. LLC, Bridgewater, NJ, USA; 2007. Health Care Professional. Dosing \& Titration. http://www.lantus.com/hcp/titration. aspx (Accessed 13 Nov 2012).

7. Benjamin EM. Self-monitoring of blood glucose: the basics. Clin Diabetes. 2002;20:45-7.

8. White RD. Patient empowerment and optimal glycemic control. Curr Med Res Opin. 2012;28: 979-89.

9. American Diabetes Association. Insulin administration. Diabetes Care. 2002;25:S112-5.

10. Peyrot M, Barnett AH, Meneghini LF, Schumm-Draeger PM. Factors associated with injection omission/non-adherence in the Global Attitudes of Patients and Physicians in Insulin Therapy Study. Diabetes Obes Metab. 2012;14:1081-7.

11. Peyrot M, Barnett AH, Meneghini LF, Schumm-Draeger PM. Insulin adherence behaviours and barriers in the multinational Global Attitudes of Patients and Physicians in insulin therapy study. Diabet Med. 2012;29:682-90.

12. Norris SL, Lau J, Smith SJ, et al. Self-management education for adults with type 2 diabetes: a meta-analysis on the effect of glycemic control. Diabetes Care. 2002;25:1159-71.

13. Kulzer B, Hermanns N, Reinecker H, Haak T. Effects of self-management training in type 2 diabetes: a randomized, prospective trial. Diabet Med. 2007;24:415-23.

14. Anderson RM, Funnell MM, Butler PM, et al. Patient empowerment: results of a randomized controlled trial. Diabetes Care. 1995;18:943-9.

15. Liebl A, Breitscheidel L, Nicolay C, Happich M. Direct costs and health-related resource utilisation in the 6 months after insulin initiation in German patients with type 2 diabetes mellitus in 2006: INSTIGATE study. Curr Med Res Opin. 2008;24:2349-58.

16. Yeaw J, Christensen TE, Groleau D, Wolden ML, Lee WC. Self-monitoring blood glucose test strip utilization in Canada. Diabetes. 2012;61(Suppl 1): A35.

17. Yeaw J, Lee WC, Wolden ML, Christensen T, Groleau D. Cost of self-monitoring of blood glucose in Canada among patients on an insulin regimen for diabetes. Diabetes Ther. 2012;3:7.

18. Yeaw J, Lee WC, Aagren M, Christensen TJ. Cost of self-monitoring of blood glucose in the United States among patients on an insulin regimen for diabetes. J Manag Care Pharm. 2012;18:21-32.
19. Heise T, Hermanski L, Nosek L, Feldman A, Rasmussen S, Haahr $\mathrm{H}$. Insulin degludec: four times lower pharmacodynamic variability than insulin glargine under steady-state conditions in type 1 diabetes. Diabetes Obes Metab. 2012;14:859-64.

20. Heise T, Nosek L, Hovelmann U, Bøttcher SG, Hastrup H, Haahr H. Insulin degludec $200 \mathrm{U} / \mathrm{mL}$ is ultra-long-acting and has a flat and stable glucose-lowering effect. Diabetes. 2012;61:A91.

21. Korsatko S, Deller S, Zahiragic S, et al. Ultra-long-acting insulin degludec: bio-equivalence and similar pharmacodynamics shown for two different formulations (U100 and U200). Diabetologia. 2011;54:S427.

22. World Medical Association. World Medical Association Declaration of Helsinki: Ethical principles for medical research involving human subjects-last amended by the 59th WMA General Assembly, Seoul; 2008. http://www.wma.net/en/ 30publications/10policies/b3/17c.pdf (Accessed 4 Jan 2013).

23. International Conference on Harmonisation. ICH Harmonised Tripartite Guideline: Guideline for Good Clinical Practice. E6 (R1), Step 4. 10-6-1996. http://www.ich.org/fileadmin/Public_Web_Site/ ICH_Products/Guidelines/Efficacy/E6_R1/Step4/ E6_R1__Guideline.pdf (Accessed 4 Jan 2013).

24. Niskanen L, Jensen LE, Råstam J, Nygaard-Pedersen L, Erichsen K, Vora JP. Randomized, multinational, open-label, 2-period, crossover comparison of biphasic insulin aspart 30 and biphasic insulin lispro 25 and pen devices in adult patients with type 2 diabetes mellitus. Clin Ther. 2004;26: $531-40$.

25. Garg S, Bailey T, DeLuzio T, Pollum D. Preference for a new prefilled insulin pen compared with the original pen. Curr Med Res Opin. 2011;27: 2323-33.

26. Garber AJ, King AB, Del Prato $S$, on behalf of the NN1250-3582 BEGIN BB T2D trial investigators, et al. Insulin degludec, an ultra-long acting basal insulin, versus insulin glargine in basal-bolus treatment with mealtime insulin aspart in type 2 diabetes (BEGIN Basal-Bolus Type 2): a phase 3, randomised, open-label, treat-to-target non-inferiority trial. Lancet. 2012;379:1498-507.

27. Zinman B, Philis-Tsimikas A, Cariou B, on behalf of the NN1250-3579 BEGIN Once Long trial investigators, et al. Insulin degludec versus insulin glargine in insulin-naïve patients with type 2 diabetes: a 1-year, randomized, treat-to-target trial (BEGIN Once Long). Diabetes Care. 2012;35: 2464-71. 
28. Bergenstal R, Bhargava A, Jain RK, et al; on behalf of the NN1250-3672 BEGIN Low Volume trial investigators. $200 \mathrm{U} / \mathrm{ml}$ insulin degludec improves glycemic control similar to insulin glargine with a low risk of hypoglycemia in insulin-naïve people with type 2 diabetes. Abstract 207. http://am. aace.com/2012/sites/all/files/abstract-061812.pdf (Accessed 19 Jan 2013).

29. Onishi Y, Ono Y, Rabl R, Endahl L, Nakamura S. Superior glycaemic control with once-daily insulin degludec/insulin aspart versus insulin glargine in Japanese adults with type 2 diabetes inadequately controlled on oral drugs: a randomized, controlled phase 3 trial. Diabetes Obes Metab. 2013 (Epub ahead of print).

30. Blonde L, Merilainen M, Karwe V, Raskin P, for the TITRATE Study Group. Patient-directed titration for achieving glycaemic goals using a once-daily basal insulin analogue: an assessment of two different fasting plasma glucose targets-the TITRATE study. Diabetes Obes Metab. 2009;11:623-31.

31. Gerstein HC, Yale J-F, Harris SB, et al. A randomized trial of adding insulin glargine vs. avoidance of insulin in people with Type 2 diabetes on either no oral glucose-lowering agents or submaximal doses of metformin and/or sulphonylureas. The Canadian INSIGHT (Implementing New Strategies with Insulin Glargine for Hyperglycaemia Treatment) study. Diabet Med. 2006;23:736-42.

32. Davies M, Lavalle-González F, Storms F, Gomis R, on behalf of the AT.LANTUS Study Group. Initiation of insulin glargine therapy in type 2 diabetes subjects suboptimally controlled on oral antidiabetic agents: results from the AT.LANTUS trial. Diab Obes Metab. 2008;10:387-99.

33. Yki-Järvinen $\mathrm{H}$, Juurinen $\mathrm{L}$, Alvarsson $\mathrm{M}$, et al. Initiate insulin by aggressive titration and education (INITIATE): a randomized study to compare initiation of insulin combination therapy in type 2 diabetic patients individually and in groups. Diabetes Care. 2007;30:1364-9.

34. Rakel RE. Improving patient acceptance and adherence in diabetes management: a focus on insulin therapy. Adv Ther. 2009;26:838-46.
35. Ross SA, Tildesley HD, Ashkenas J. Barriers to effective insulin treatment: the persistence of poor glycemic control in type 2 diabetes. Curr Med Res Opin. 2011;27:13-20.

36. Reimer T, Hohberg C, Pfützner AH, Jørgensen C, Jensen $\mathrm{KH}$, Pfützner A. Intuitiveness, instruction time, and patient acceptance of a prefilled insulin delivery device and a reusable insulin delivery device in a randomized, open-label, crossover handling study in patients with type 2 diabetes. Clin Ther. 2008;30:2252-62.

37. Rubin RR, Peyrot M. Factors affecting use of insulin pens by patients with type 2 diabetes. Diabetes Care. 2008;31:430-2.

38. Peyrot M, Rubin RR. Factors associated with persistence and resumption of insulin pen use for patients with type 2 diabetes. Diabetes Technol Ther. 2011;13:43-8.

39. Oyer D, Narendran P, Qvist $M$, Niemeyer $M$, Nadeau DA. Ease of use and preference of a new versus widely available pre-filled insulin pen assessed by people with diabetes, physicians and nurses. Expert Opin Drug Deliv. 2011;8:1259-69.

40. Bailey T, Thurman J, Niemeyer M, Schmeisl G. Usability and preference evaluation of a prefilled insulin pen with a novel injection mechanism by people with diabetes and healthcare professionals. Curr Med Res Opin. 2011;27:2043-52.

41. Nadeau DA, Campos C, Niemeyer M, Bailey T. Healthcare professional and patient assessment of a new prefilled insulin pen versus two widely available prefilled insulin pens for ease of use, teaching and learning. Curr Med Res Opin. 2012;28:3-13.

42. Lajara R, Guerrero G, Thurman J. Healthcare professional and patient perceptions of a new prefilled insulin pen versus vial and syringe. Expert Opin Drug Deliv. 2012;9:1181-96.

43. Bailey T, Campos C. FlexTouch ${ }^{\circledR}$ for the delivery of insulin: technical attributes and perception among patients and healthcare professionals. Expert Rev Med Devices. 2012;9:209-17. 